We are still in a growth phase and we are very careful not to grow too fast," says Jean Frechet, vice president for research at KAUST. "We want to grow in quality before quantity, and we want to do it right."

Frechet himself was recruited from the University of California, Berkeley. When he was approached in 2009, he refused an offer because he had never heard of KAUST.

But he changed his mind after visiting the university, seeing the facilities and meeting other faculty members. "It was very exciting", he recalls. "Sometimes you get the opportunity to do something that you will not get again."

The region's institute with the highest WFC is the Weizmann Institute of Science in Rehovot, Israel.

\section{"SAUDI ARABIA IS CHARACTERIZED BY MATERIAL SCIENCE RESOURCES."}

Notably, it has published 12 papers in Nature and Science, more than all other institutes in the region, and papers in these journals comprise $4.4 \%$ of its output, compared to $0.6 \%$ for KAUST. Such a record is the result of progressive hiring policies, says Daniel Zajfman, president of the Weizmann Institute. "We do not know what the next important thing in science is, but we can know who are the outstanding scientists."

KAUST and Weizmann have very different research profiles. Life sciences research at KAUST is scant, as it is across Saudi Arabia (see 'Research strengths'), whereas the Israeli institute has a more even split between chemistry and life and physical sciences. "Saudi Arabia is very much characterized by material science due to its natural resources," explains Frechet, adding that KAUST modelled itself on the California Institute of Technology (Caltech), which is also heavily focused on physical sciences.

The Weizmann Institute's science is also much more visible on social media, with five papers (four in the life sciences) receiving a score on altmetrics.com - a new measure of a paper's impact, determined by article views, downloads and references in social media and news sources - in excess of 100. Its top article was a Nature paper authored by three Weizmann researchers collaborating with six researchers from the University of Cambridge and the United Kingdom's Babraham Institute. This paper challenged previous views about the shape of chromosomes. In contrast, KAUST's highest paper achieved a score of 47 for describing a new material for scrubbing carbon dioxide from the air.

\section{IRAN}

\section{Institute for Research in Fundamental Sciences}

Located in the Farmanieh district in northern Tehran, the Institute for Research in Fundamental Sciences (IPM) is Iran's leading institution in the index. It is one of the few top 10 institutes in the region that isn't in Israel or Saudi Arabia. IPM, credited with bringing the internet to Iran, is almost completely focused on physical sciences research, particularly involving the Large Hadron Collider at CERN (nearly half its papers are in the Journal of High

Energy Physics)

Seventeen IPM researchers participate in various particle physics experiments, mainly at CERN's Hadron Calorimeter. Such collaborative work is seen in its high ratio of article count (AC) to weigh fractional count (WFC).

IPM is also trying to engage and stimulate local research through various projects with Iranian universities and research centres. One example is the Iranian Light Source Facility in the northwest Qazvin province, which will house a dedicated synchrotron accelerator once it is complete in late 2018.

\title{
Central \& South Asia
}

\section{Asia's traditional strengths in chemistry and physical sciences continue to power scientific pursuits and collaborations in Central and South Asian countries.}

\section{ARTICLE COUNT (AC): 1,574 FRACTIONAL COUNT (FC): 986 WEIGHTED FRACTIONAL COUNT (WFC): 879}

A sia's historic love affair with chemistry and physics is noteworthy. So much so that the topic is a common conversation starter when international scientists meet at a conference dinner.

So it's not surprising that, in sharp contrast with global publication trends in the Nature Index, 2013 papers from the Central and South Asian region slant steeply toward chemistry and the physical sciences (see 'Research strengths'). The scientific output of the region is dominated by India - with a population of 1.3 billion and growing - towering over the region's secondhighest performing country and her politically volatile neighbour, Pakistan.

Transitioning from a developing country to an emerging economic superpower, India is experiencing an attendant surge in its share of the world's scientific publications. The recovery is largely the result of liberalization, part of the country's rapid economic growth post-2000. Though allocated funds for science and technology have stagnated at around $1 \%$ of GDP over the last two decades, the economic boom means that the absolute amount of money available for scientific research and development has increased. In the 2014 annual budget, India announced a $4 \%$ hike in allocations to sciencerelated ministries setting aside 362.69 billion rupees (US\$6 billion) for research.

Nandula Raghuram, a keen metrics watcher and professor at New Delhi-based Guru Govind Singh Indraprastha University, says, "In many consecutive meetings of the Indian Science
Congress, our prime ministers have expressed the need to double the investment for science and technology and bring it to $2 \%$ of GDP. It is shameful that this has never happened."

The Indian government has been urging the private sector to invest more in science but Raghuram says private investment should not be relied on to substitute government funding, which accounts for the lion's share of science capital in India.

Pakistan, which began its life as an independent country a day before India in August 1947, did not have many scientific institutions when it struck out alone. Despite years of instability and political turmoil it now has a handful of credible scientific institutions. The country spends $0.59 \%$ of GDP on science and technology (S\&T) 
and is aiming to ramp that up to $2 \%$, by 2020 . The country's new science and technology policy tries to connect science with socio-economic development, primarily concentrating on demand-driven research that might help the economy, and through international partnerships. It has some way to go: although India and Pakistan both have roughly the same number of researchers per capita (about 150-160 per million of population), India's scientists are more efficient, producing more than four times as many papers each (see 'Researcher efficiency').

\section{"PAKISTAN'S POLITICS ECLIPSE DEVELOPMENTAL ENDEAVOURS."}

Pakistan's political uncertainties continue to eclipse all its developmental endeavours. In a national science and technology policy released in 2012, then science minister Mir Changez Khan Jamali conceded that these exigencies have relegated S\&T efforts to the back burner. In the baby steps that Pakistan is taking to shape its research efforts, the focus is on using science to boost the economy through technology transfer projects in metrology, environment, health, energy, biotechnology, agriculture, genetic engineering, electronics and nanotechnology.

Pakistan's Quaid-i-Azam University has an article count (AC) of 52 in the index, the vast majority in the physical sciences (86.1\%). The success stems mostly from its natural science faculty, a central part of the university since its foundation. Faculty dean, Mohammed Zakaullah, says most of its research is highly applied.

Two papers in the journal Applied Physics Letters that best show the university's strength, wholly authored by its researchers, detail behaviours of "relaxors" - a class of materials that change shape when an electric field is applied - both of which have immediate applications.

\section{SUCCESS STORY}

The Indian success story contains highlights of scientific brilliance in recent years, especially in material science, nanosciences and astrophysics, at its many Indian Institutes of Technology (IITs). These technology schools have the highest WFC, which gives a measure of the relative contribution of an institution to each paper, in the region, followed by the government-funded laboratories of the Council of Scientific and Industrial Research and the Indian Institutes of Science Education and Research (IISER). Researchers from the IISERs contributed to three papers in Nature and Science in 2013, the highest contribution for any Indian institution; the country as a whole only managed 11 papers.

IITs and IISERs are conglomerates or groups of institutes. The standalone institute that shines through is the Indian Institute of Science (IISc) with its formidable chemistry and physical sciences departments producing the highest WFC (83) of the country's individual centres. Institute director Anurag Kumar attributes this success to the fact that new faculty members are provided with start-up research funding, "so that they can get their research programmes off the ground without having to wait for their first grants." IISc also has an ongoing programme that provides seed grants to groups, which most often go on to win large value grants. Of the institution's 132 articles, 60 were wholly authored in-house (an FC of 1), an impressive display of independence. Five of these were in Physical Review Letters, including a paper that upped the theoretical mass limit for a star to turn into a type 1a supernova, which did particularly well on Twitter, according to altmetrics.com data.

In the field of physical science, meanwhile, the Tata Institute of Fundamental Research out-produced IISc in 2013, with a WFC second only to the combined IITs. With its stronghold - fundamental research in particle physics and astrophysics - Tata scientists made a mark with their contribution to the CERN experiments that led to the discovery of the Higgs-boson particle.

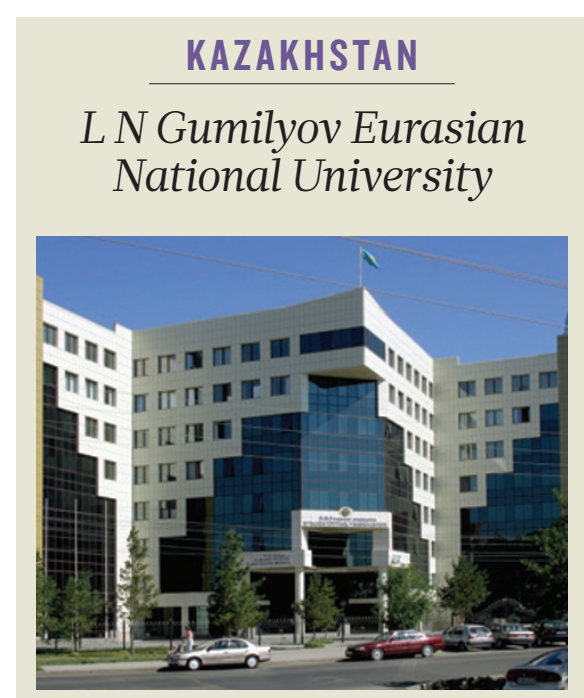

Kazakhstan, a seat of learning in medieval times

Named after Eurasian scientist Lev Nikolayevich Gumilyov, this national university focuses on the integration of science, education and industry. A former Soviet republic, oil-rich Kazakhstan was considered a major seat of scientific learning in the region in medieval times. Recently, in just a few years, Kazakhstan has more than doubled its science spending from KZT20 billion (US\$109 million) in 2010 to KTZ53 billion ( $\$ 290$ million) in 2013 , or around $1 \%$ of the country's GDP. The university is also expected to benefit from Kazakh science minister Aslan Sarinzhipov's recent announcement of increasing science spending to 3\% of GDP by 2050.

The university might only have six papers in this year's Nature Index, but it is tackling difficult and eclectic areas of physics. Its top paper, authored by three researchers (one with a joint affiliation) from Gumilyov, concerns new exact solutions for static wormholes.

\section{CENTRAL \& SOUTH ASIA ANALYSIS}

Countries' weighted fractional count (WFC)

Nine countries in this region appear in the index, with India dominating.

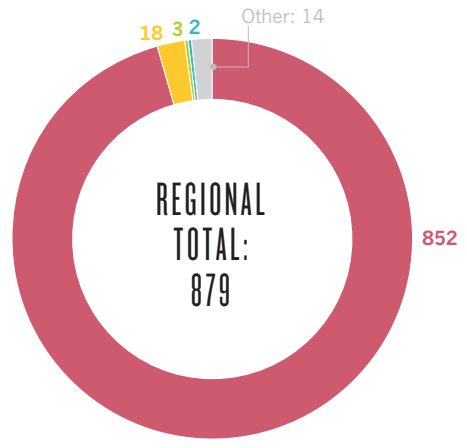

India

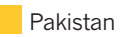

Kazakhstan Bangladesh

Research strengths

India and Pakistan have vastly different priorities for their research ${ }^{2}$.
Researcher efficiency

WFC per 1,000 researchers ${ }^{1}$.

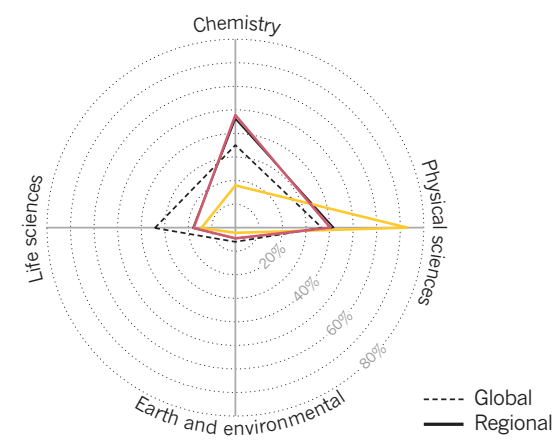

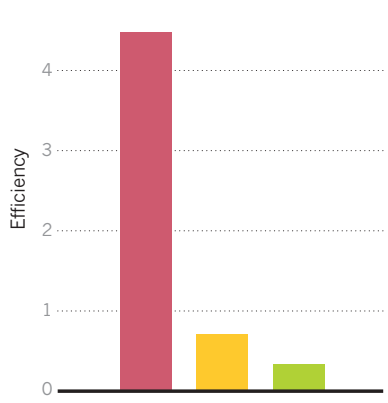

